\title{
Prevalence of Antimicrobial Resistance and Hemolytic Phenotypes in Culturable Arctic Bacteria
}

\author{
Diana C. Mogrovejo ${ }^{1 \dagger}$, Laura Perini2*t, Cene Gostinčar²,3, Kristina Sepčić2 , Martina Turk², \\ Jerneja Ambrožič-Avguštin², Florian H. H. Brill' and Nina Gunde-Cimerman² \\ ${ }^{1}$ Dr. Brill + Partner GmbH Institut für Hygiene und Mikrobiologie, Hamburg, Germany, ${ }^{2}$ Department of Biology, Biotechnical \\ Faculty, University of Ljubljana, Ljubljana, Slovenia, ${ }^{3}$ Lars Bolund Institute of Regenerative Medicine, Qingdao, China
}

OPEN ACCESS

Edited by:

David Anthony Pearce,

Northumbria University, United Kingdom

Reviewed by:

Rosa Del Campo,

Ramón y Cajal Health Research Institute, Spain

William Hugo Gaze,

University of Exeter, United Kingdom

*Correspondence:

Laura Perin

lauraperini89@gmail.com

laura.perini@bf.uni-lj.si

tThese authors have contributed equally to this work and share first authorship

Specialty section:

This article was submitted to Extreme Microbiology,

a section of the journal

Frontiers in Microbiology

Received: 19 September 2019

Accepted: 16 March 2020

Published: 03 April 2020

Citation:

Mogrovejo DC, Perini L,

Gostinčar C, Sepčić K, Turk M, Ambrožič-Avguštin J, Brill FHH and

Gunde-Cimerman N (2020)

Prevalence of Antimicrobial

Resistance and Hemolytic

Phenotypes in Culturable Arctic Bacteria. Front. Microbiol. 11:570.

doi: 10.3389/fmicb.2020.00570
Many Arctic biomes, which are populated with abundant and diverse microbial life, are under threat: climate change and warming temperatures have raised concerns about diversity loss and possible emergence of pathogenic microorganisms. At present, there is little information on the occurrence of Arctic virulence-associated phenotypes. In this study we worked with 118 strains of bacteria (from 10 sampling sites in the Arctic region, located in Greenland and the Svalbard Archipelago) isolated using R2A medium. These strains belong to 4 phyla and represent 36 different bacterial genera. Phenotypic resistance to 8 clinically important antimicrobials (ampicillin, chloramphenicol, ciprofloxacin, cefotaxime, erythromycin, imipenem, kanamycin, and tetracycline) and thermotolerance range were determined. In addition, a screening of all isolates on blood agar media and erythrocytes suspension of bovine and sheep erythrocytes for virulence-linked hemolytic activity was performed. Although antimicrobial resistance profiles varied among the isolates, they were consistent within bacterial families and genera. Interestingly, a high number of isolates (83/104) were resistant to the tested concentration of imipenem ( $4 \mathrm{mg} / \mathrm{L}$ ). In addition, one third of the isolates showed hemolytic activity on blood agar, however, in only $5 \%$ of the isolates hemolytic activity was also observed in the cell extracts when added to erythrocyte suspensions for $60 \mathrm{~min}$. The observed microbial phenotypes contribute to our understanding of the presence of virulence-associated factors in the Arctic environments, while highlighting the potential risks associated with changes in the polar areas in the light of climate change.

Keywords: Arctic, extremely cold environment, pathogens, hemolysis, antimicrobial resistance

\section{INTRODUCTION}

The Arctic region, once considered a "biological desert," is now regarded as a rich and dynamic ecosystem (Krajick, 2001; Post et al., 2009), characterized by diverse biomes that harbor species from all three domains of life (Anesio and Laybourn-Parry, 2012). Until the onset of global warming, the changes of extreme Arctic biomes progressed slowly, compared to temperate and 
tropical regions, and served as proxies for unperturbed natural environments. In the last decades, researchers increasingly recognized the opportunities that the Arctic biomes represent for studying of diverse microbial communities and their interactions (Post et al., 2009).

Ongoing climate change is drastically altering our planet, increasing global air and ocean temperatures, causing widespread melting of snow and ice and rising global average sea levels (Intergovernmental Panel on Climate Change [IPCC], 2007). While every environment on Earth is influenced, Arctic environments are particularly affected and, in fact, their average temperatures have increased almost twice as fast as the global warming rate in the past 100 years (Intergovernmental Panel on Climate Change [IPCC], 2007).

Despite the fact that climate change directly affects microorganisms, microbial life is rarely studied in this context (Cavicchioli et al., 2019). When their interactions with other species are perturbed, the resulting pressures strongly influence microbial community composition and function and might play a role in the expression of bacterial virulence factors (Livermore, 2003). Additionally, altered climatic conditions might enable virulent and/or antimicrobial resistant microbes, originating from temperate regions, to reach previously pristine and unperturbed Arctic environments, spreading virulence factors and resistance genes (Altizer et al., 2013).

Antimicrobial resistance is the natural or acquired capacity of microorganisms to withstand the effects of an antimicrobial drug (Davies and Davies, 2010; World Health Organization [WHO], 2014). In fact, resistance to antimicrobials is widely considered to be one of the biggest health challenges of our time, leading to higher medical costs, prolonged hospital stays, and increased mortality rates (World Health Organization [WHO], 2014). Several studies have confirmed the presence of antimicrobial resistance genotypes and phenotypes in microorganisms from cold environments and suggested that the polar regions can be considered benchmarks for the study of antimicrobial resistance in pristine non-clinical environments (Yuan et al., 2014; Tam et al., 2015; Agnew et al., 2016; McCann et al., 2019).

Hemolysins, considered an important virulence factor, are compounds produced by a variety of bacterial species. These compounds are responsible for membrane damage, cell lysis and destruction of neighboring cells and tissues in order to provide nutrients, mainly iron, for the toxin-producing bacteria (Bullen et al., 2005). Iron is an essential element for living organisms as it plays catalytic, regulatory and structural roles in the cell and many authors have also pointed out its important role as a virulence regulator for commensal and pathogenic microorganisms (Messenger and Barclay, 1983; Litwin and Calderwood, 1993; Zughaier and Cornelis, 2018). Even though they are studied as major virulence factors in infection models of laboratory animals (Bhakdi et al., 1994; Bayley, 1997; Tomita and Kamio, 1997) and are commonly associated with pathogenic bacteria, the expression of hemolysins has rarely been assessed in bacterial isolates from environmental samples (Bevivino et al., 2002; González-Rodríguez et al., 2007) and, to the best of our knowledge, very few studies exist about the hemolytic activity of Arctic bacterial species, e.g., Mogrovejo-Arias et al. (2020).
Finally, an important bacterial trait is the microorganism's ability to grow at $37^{\circ} \mathrm{C}$, the optimum temperature for most of human pathogens that allows microbial colonization, and is thus a prerequisite for pathogenic microbe-human interactions (Madigan et al., 2012). Research of Arctic microbes usually uses growth temperatures lower than $37^{\circ} \mathrm{C}$, e.g., $4,15,20$, or $27^{\circ} \mathrm{C}$ (Wiebe et al., 1992; Amato et al., 2007; Tam et al., 2015) and temperatures above $30^{\circ} \mathrm{C}$ are rarely used, as these are usually too high for the optimal growth of even the psychrotolerant species (Moyer and Morita, 2007).

Environmental or commensal microorganisms might become pathogenic under stressful conditions since bacterial species respond to environmental stress in a variety of ways, e.g., acceleration of horizontal gene transfer (Marshall et al., 2009). Accordingly, genes encoding traits that occur naturally in the environment, such as antimicrobial resistance and hemolytic activity, can be transferred between habitats by bacteria, bacteriophages or mobile genetic elements, resulting in a globalscale redistribution of resistance and virulence factors/genes (Marshall et al., 2009; Davies and Davies, 2010).

One of the main indirect effects of climate change could be the increase of infectious diseases (Kurane, 2010). The Arctic in this context represents an important source of microorganisms and mobile genetic elements that could transit into more human-associated environments (Edwards, 2015). Thus research on virulence-associated phenotypes in natural, non-clinical environments is necessary to understand the possible implications of the climate changes for public health (Martínez, 2008).

In the present study of bacterial isolates from the Arctic region, we investigated three phenotypes commonly associated with pathogenic bacteria, i.e., growth at $37^{\circ} \mathrm{C}$, the hemolytic activity on blood agar plates at different temperatures as well as on erythrocyte suspensions and resistance to 8 different, commonly used and clinically relevant antimicrobials.

\section{MATERIALS AND METHODS}

\section{Site and Samples Description}

Samplings were performed during 2016 and 2017 summer/winter seasons in the south-western margin of Greenland, the Greenland Ice Sheet, and Svalbard, the areas of Ny-Ålesund and Longyearbyen (Perini et al., 2019a,b; Mogrovejo-Arias et al., 2020). The bacterial composition of these ecosystems has been studied extensively by culture-dependent as well as cultureindependent methodologies (Perini et al., 2019a,b; MogrovejoArias et al., 2020).

Glacial and subglacial ice, snow, lake ice, tap water, glacial meltwater, sediment, pond and sea water samples were collected from the locations shown in Figure $\mathbf{1}$ and described in Table $\mathbf{1 .}$ Ice, snow, cryoconite, and sediment samples were collected using disposable sterile nitrile gloves and surface-sterilized tools and transferred into sterile Whirl-Pak ${ }^{\circledR}$ plastic bags. For snow and soil samples, $5 \mathrm{~cm}$ of the surface were discarded and a disinfected shovel or sterile spoon was used to store the sample in the sterile plastic bags. Tap water, glacial meltwater, pond 


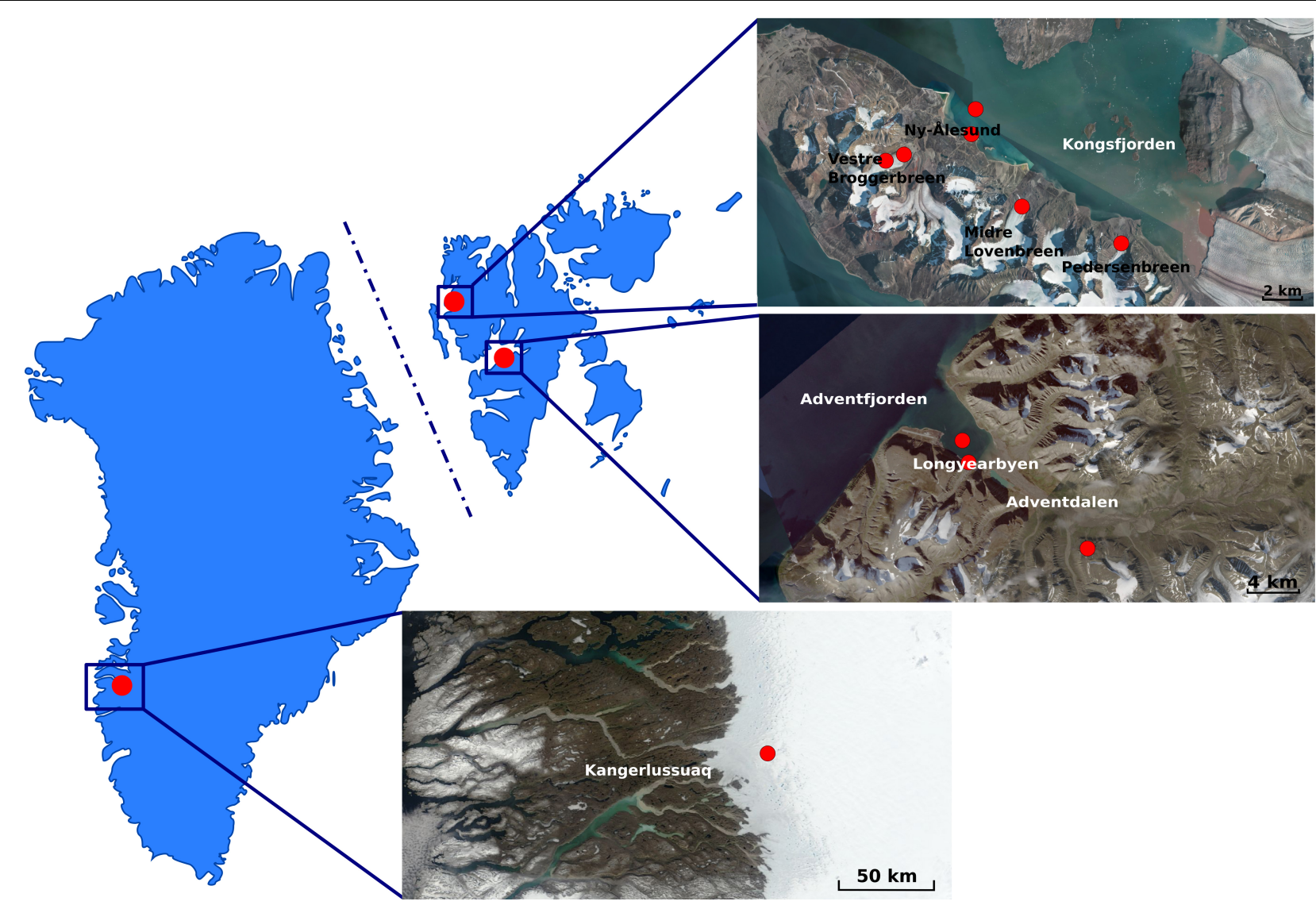

FIGURE 1 | Maps of Greenland (Left) and Svalbard (Right) Archipelago (Norway) indicating the areas where fieldwork was conducted. Red dots in the satellite images indicate the sampling sites. Greenland map was acquired as an image from Modis Satellite. Svalbard map was adapted as an image from TopoSvalbard credit NPI/USGS Landsat, courtesy of the Norwegian Polar Institute (available at: https://toposvalbard.npolar.no). Greenland and the Svalbard Archipelago are not drawn to scale.

and sea water were collected into plastic bottles previously washed with $15 \%$ hydrogen peroxide, followed by three washes with sterile water and three washes with the sample. Samples were processed as outlined by Mogrovejo-Arias et al. (2020) or processed within $24 \mathrm{~h}$ from their collection at the primary ice camp on the Greenland Ice Sheet, the NERC Arctic Research Station (Ny-Ålesund), or the University Centre in Svalbard (UNIS; Longyearbyen).

\section{Cultivation and Isolation of Bacteria}

Snow, supraglacial and subglacial ice were melted at $+4^{\circ} \mathrm{C}$ in the dark prior filtration. After the outer surface layer of subglacial ice was melted, it was discarded, the remaining ice was washed with sterile water and only the second round of meltwater was used for analyses. Serial dilutions were used for soil and sediment samples. Water samples were filtered through Millipore membrane filters $(0.45 \mu \mathrm{m}$ pore size $)$ in duplicates. Filters were placed onto R2A (BioLife), an oligotrophic medium for heterotrophic microorganisms.

Plates of all sample types were incubated at 5, 10, 1517 , and $37^{\circ} \mathrm{C}$ for up to 4 months in sterile plastic bags to preserve the humidity of the agar media. Negative control plates were prepared with sterile water frozen prior to culturing and processed as the samples. Two control agar plates were streaked for each testing temperature and incubated in the same conditions and for the same duration as the samples. Liquid and enrichment cultures were not used.

\section{Bacterial Identification}

Morphologically different colonies were selected and streaked onto fresh R2A plates in order to obtain pure cultures. The plates were incubated at the initial isolation temperature of each isolate and, in addition, at $37^{\circ} \mathrm{C}$. DNA was extracted using PrepMan Ultra reagent (Applied Biosystems) according to the manufacturer instructions. 16S rRNA gene was amplified with 27f-lane, 1492R, 8F, and 1541R primers (Tam et al., 2015; Perini et al., 2019a; Mogrovejo-Arias et al., 2020). The 16S nucleotide amplicons were Sanger-sequenced by Microsynth AG (Switzerland). The resulting sequences were analyzed using MUSCLE software (Edgar, 2004) implemented in the MEGA7 package (Kumar et al., 2016) and compared against the GenBank database using the BLAST software. ${ }^{1}$ The $16 \mathrm{~S}$ rDNA sequences

\footnotetext{
${ }^{1}$ https://blast.ncbi.nlm.nih.gov/Blast.cgi
} 
TABLE 1 | Sample types and GPS coordinates of the sampling locations for this study.

\begin{tabular}{|c|c|c|c|c|c|}
\hline Sample type & Site description & Area, country & Season & Year & GPS coordinates \\
\hline Dispersed cryoconite & Ice camp on GrIS & Kangerlussuaq, Greenland & Summer & 2016 & $67^{\circ} 04^{\prime} 43^{\prime \prime} \mathrm{N} 49^{\circ} 20^{\prime} 29^{\prime \prime} \mathrm{W}$ \\
\hline Supraglacial ice - clear ice & & & & 2016,2017 & \\
\hline $\begin{array}{l}\text { Supraglacial ice with high } \\
\text { biomass inclusions of dark glacial } \\
\text { algae - dark ice }\end{array}$ & & & & 2016, 2017 & \\
\hline Cryoconite & & & & 2016, 2017 & \\
\hline Supraglacial water & & & & 2017 & \\
\hline \multirow[t]{4}{*}{ Snow } & Ice camp on GrlS & Kangerlussuaq, Greenland & Summer & 2017 & $67^{\circ} 04^{\prime} 43^{\prime \prime} \mathrm{N} 49^{\circ} 20^{\prime} 29^{\prime \prime} \mathrm{W}$ \\
\hline & Seasonal pond, Adventdalen & Longyearbyen, Svalbard & Winter & 2016 & $78^{\circ} 09^{\prime} 24^{\prime \prime} \mathrm{N} 16^{\circ} 01^{\prime} 59^{\prime \prime} \mathrm{E}$ \\
\hline & Midtre Lovénbreen & Ny-Ålesund, Svalbard & Summer & 2017 & $78^{\circ} 53^{\prime} 08^{\prime \prime} \mathrm{N} 12^{\circ} 02^{\prime} 44^{\prime \prime} \mathrm{E}$ \\
\hline & Vestre Brøggerbreen & Ny-Ålesund, Svalbard & Summer & 2017 & $78^{\circ} 54^{\prime} 42^{\prime \prime} \mathrm{N} 11^{\circ} 43^{\prime} 42^{\prime \prime} \mathrm{E}$ \\
\hline \multirow[t]{3}{*}{ Subglacial ice } & Midtre Lovénbreen & Ny-Ålesund, Svalbard & Summer & 2017 & $78^{\circ} 53^{\prime} 37^{\prime \prime} \mathrm{N} 12^{\circ} 04^{\prime} 13^{\prime \prime} \mathrm{E}$ \\
\hline & Vestre Brøggerbreen & Ny-Ålesund, Svalbard & Summer & 2017 & $78^{\circ} 54^{\prime} 55^{\prime \prime} \mathrm{N} 11^{\circ} 45^{\prime} 48^{\prime \prime} \mathrm{E}$ \\
\hline & Pedersenbreen & Ny-Ålesund, Svalbard & Summer & 2017 & $78^{\circ} 52^{\prime} 46^{\prime \prime} \mathrm{N} 12^{\circ} 17^{\prime} 57^{\prime \prime} \mathrm{E}$ \\
\hline Tap water & UNIS & Longyearbyen, Svalbard & Winter & 2016 & 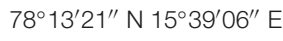 \\
\hline \multirow[t]{2}{*}{ Glacial melt water } & Midtre Lovénbreen & Ny-Ålesund, Svalbard & Summer & 2017 & $78^{\circ} 53^{\prime} 25^{\prime \prime} \mathrm{N} 12^{\circ} 03^{\prime} 15^{\prime \prime} \mathrm{E}$ \\
\hline & & & & & $78^{\circ} 53^{\prime} 36^{\prime \prime} \mathrm{N} 12^{\circ} 04^{\prime} 13^{\prime \prime} \mathrm{E}$ \\
\hline Pond water & Ny-Ålesund area & Ny-Ålesund, Svalbard & Summer & 2017 & $78^{\circ} 55^{\prime} 34^{\prime \prime} \mathrm{N} 11^{\circ} 56^{\prime} 21^{\prime \prime} \mathrm{E}$ \\
\hline \multirow[t]{2}{*}{ Sea water } & Adventfjorden & Longyearbyen, Svalbard & Winter & 2016 & $78^{\circ} 14^{\prime} 27^{\prime \prime} \mathrm{N} 15^{\circ} 36^{\prime} 59^{\prime \prime} \mathrm{E}$ \\
\hline & Kongsfjorden & Ny-Ålesund, Svalbard & Summer & 2017 & $78^{\circ} 55^{\prime} 33^{\prime \prime} \mathrm{N} 12^{\circ} 02^{\prime} 29^{\prime \prime} \mathrm{E}$ \\
\hline \multirow[t]{2}{*}{ Soil } & Midtre Lovénbreen forefield & Ny-Ålesund, Svalbard & Summer & 2017 & $78^{\circ} 53^{\prime} 54^{\prime \prime} \mathrm{N} 12^{\circ} 03^{\prime} 59^{\prime \prime} \mathrm{E}$ \\
\hline & Vestre Brøggerbreen forefield & Ny-Ålesund, Svalbard & Summer & 2017 & $78^{\circ} 55^{\prime} 20^{\prime \prime} \mathrm{N} 11^{\circ} 46^{\prime} 38^{\prime \prime} \mathrm{E}$ \\
\hline \multirow[t]{2}{*}{ Sediment } & Marine sediment, Adventfjorden & Longyearbyen, Svalbard & Winter & 2016 & $78^{\circ} 14^{\prime} 27^{\prime \prime} \mathrm{N} 15^{\circ} 36^{\prime} 59^{\prime \prime} \mathrm{E}$ \\
\hline & Pond sediment, Ny-Ålesund area & Ny-Ålesund, Svalbard & Summer & 2017 & $78^{\circ} 55^{\prime} 34^{\prime \prime} \mathrm{N} 11^{\circ} 56^{\prime} 21^{\prime \prime} \mathrm{E}$ \\
\hline
\end{tabular}

obtained in this study were deposited in the NCBI GenBank nucleotide database. All isolated strains used in this study have been deposited in the Ex Culture Collection of the Infrastructural Centre Mycosmo (MRIC UL) at the Department of Biology, Biotechnical Faculty, University of Ljubljana, Slovenia. Information on all isolates and accession numbers for their 16S rRNA sequences are listed in Supplementary Table S1.

\section{Hemolytic Assay on Blood Agar}

Bacterial isolates were cultured on Blood Agar Base (Fluka Analytical) containing $5 \%$ of sterile sheep or bovine blood and incubated at +15 and $+37^{\circ} \mathrm{C}$ for up to 7 days. The use of human blood is generally discouraged (Buxton, 2005) and thus, it was not used in our experiments. The isolates were revived from stock cultures from the Ex Culture Collection of the Infrastructural Centre Mycosmo (MRIC UL), University of Ljubljana. Only actively growing cultures were tested. As controls, the following strains revived from the Ex Culture Collection of the Infrastructural Centre Mycosmo (MRIC UL), University of Ljubljana were used: EXB V-53 Enterococcus faecalis (no hemolysis, referred to as $\gamma$-hemolysis), EXB V-59 Streptococcus pyogenes ( $\beta$-hemolysis), EXB V-62 Streptococcus pneumoniae ( $\alpha$-hemolysis).

\section{Hemolytic Assay With Erythrocyte Suspension}

Hemolytic activity of organic bacterial extracts was tested in real time using bovine and sheep erythrocyte suspensions rather than blood agar. Bacterial cultures (118 environmental and 3 control strains described in Supplementary Table S2) were grown in sterile Falcon tubes containing $20 \mathrm{~mL}$ of Nutrient Broth (BioLife). Tubes were shaken at $150 \mathrm{rpm}$ and +15 or $+25^{\circ} \mathrm{C}$, based on their isolation temperature, for 3 days. Cultures were then centrifuged for $5 \mathrm{~min}$ at $12,000 \times \mathrm{g}$, supernatant was discarded, and biomass was resuspended in $5 \mathrm{~mL}$ of non-denaturated $96 \%$ ethanol. Suspensions were vortexed for $5 \mathrm{sec}$, sonicated (40\% amplitude, $20 \mathrm{~s})$ to lyse the cells and shaken $(150 \mathrm{rpm})$ at room temperature for $30 \mathrm{~min}$. Suspensions were subsequently centrifuged (5 min at $12,000 \times g)$, the supernatants were transferred into preweighted sterile Falcon tubes and the ethanol was evaporated under chemical fume hood in a flow of nitrogen gas. The dry weight of the crude extracts was determined gravimetrically, and the extracts were resuspended in an appropriate amount of nondenaturated $96 \%$ ethanol to a standard final concentration of $1 \mathrm{mg}$ extract dry weight/mL.

Hemolytic activity was measured by a turbidimetric method using a microplate VIS absorption reader (Dynex Technologies, United States). Different volumes ( $0-25 \mu \mathrm{L})$ of ethanolic extracts, or of $96 \%$ ethanol alone, were pipetted into the wells on the 96well microtiter plate, and combined with the appropriate volume of erythrocyte buffer $(0.13 \mathrm{M} \mathrm{NaCl}, 0.02 \mathrm{M}$ Tris, $\mathrm{pH}=7.4)$ to obtain different final concentrations of the extract $(0-250 \mu \mathrm{g} / \mathrm{mL})$ in the $100 \mu \mathrm{L}$ final volume. Right before measurement, $100 \mu \mathrm{L}$ of bovine or sheep erythrocytes suspension in erythrocyte buffer $(\mathrm{OD}=0.5$ at $630 \mathrm{~nm})$ was added into the wells. The decrease in apparent absorbance was measured for $60 \mathrm{~min}$, in $30 \mathrm{~s}$ intervals, to determine the $t_{50}$ (time necessary for 
$50 \%$ hemolysis). The hemolytic activity was expressed as $1 / t_{50}$ $\left(\min ^{-1}\right)$. When tested alone, ethanol did not induce any visible hemolysis during the $60 \mathrm{~min}$.

\section{Antimicrobial Susceptibility Test}

Bacteria were cultured on Nutrient Agar (BioLife) plates containing 8 different commonly used antimicrobials and incubated at 15 or $25^{\circ} \mathrm{C}$, based on the initial isolation temperature of each isolate. Results were observed as soon as the bacterial growth appeared (between 1 and 7 days). The following antimicrobials were used: ampicillin (AMP) $100 \mathrm{mg} / \mathrm{L}$; chloramphenicol (CHL) $25 \mathrm{mg} / \mathrm{L}$; cefotaxime (CTX) $2 \mathrm{mg} / \mathrm{L}$; ciprofloxacin (CIP) $0.25 \mathrm{mg} / \mathrm{L}$; erythromycin (ERY) $15 \mathrm{mg} / \mathrm{L}$; imipenem (IPM) $4 \mathrm{mg} / \mathrm{L}$; kanamycin (KAN) $50 \mathrm{mg} / \mathrm{L}$; tetracycline (TET) $10 \mathrm{mg} / \mathrm{L}$. As positive controls, wild type Escherichia coli strains EXB L-4239 A5 and EXB L-4240 A6 isolated from poultry and with known resistance profile were used [Ex Culture Collection of the Infrastructural Centre Mycosmo (MRIC UL), University of Ljubljana]. Imipenemresistant strains were inoculated on nutrient agar plates with gradually increasing IPM concentrations $(4,6,8$, and $10 \mathrm{mg} / \mathrm{L})$. Strains that showed resistance to higher concentrations were further inoculated in duplicate on $\mathrm{CHROMID}^{\circledR}$ CARBA SMART Agar (BioMérieux, France) and incubated at $15^{\circ} \mathrm{C}$ to screen for the production of specific carbapenemases: class A Klebsiella pneumoniae carbapenemases or KPC; Class B metallo- $\beta$-lactamases or MBL including New Delhi metallo$\beta$-lactamases, NDM and Class D OXA-48-like carbapenemases (van Duin and Doi, 2017).

\section{RESULTS}

\section{Bacterial Isolation and Identification}

A total of 290 isolates were obtained from all the samples after incubation (Supplementary Table S1). Nutrient-rich samples, i.e., dark ice, cryoconite, sediment and soil, yielded the majority of isolates (159/290). The isolates belonged to four different phyla: Proteobacteria (104/290), Firmicutes (81/290), Actinobacteria (77/290), and Bacteroidetes (28/290). The most common genera in each phylum were: Pseudomonas (39/104), Bacillus (49/81), Cryobacterium (17/77), and Flavobacterium (21/28), respectively. Gram-positive isolates were slightly more frequent $(158 / 290)$ than Gram-negative (132/290).

Based on 16S rDNA identification, abundance and morphological characteristics, 118 unique strains were selected for further tests (Supplementary Table S2). Bacillus sp. and Pseudomonas sp. were the most abundant genera in this study (38/118), accounting for more than $30 \%$ of the isolates selected for the tests. The majority of the chosen isolates (87/118) were psychrotolerant and were obtained at incubation temperatures of $15-17^{\circ} \mathrm{C}$, followed by 17 mesophiles from incubation at $37^{\circ} \mathrm{C}$ and 14 psychrophiles obtained from incubation at $5-10^{\circ} \mathrm{C}$.

Interestingly, 11 isolates obtained at low incubation temperatures $\left(5-10^{\circ} \mathrm{C}\right.$ ) belonging to the genera Pedobacter (L1969 and L-1973), Sphingomonas (L-1972), Raoultella (L-1980), Flavobacterium (L-1981), Pseudomonas (L-1983, N40, and N71),
Leifsonia (An34), Salinibacterium (S58), and Microbacterium (S60) showed some degree of growth at $37^{\circ} \mathrm{C}$ on $\mathrm{R} 2 \mathrm{~A}$. Out of the 87 psychrotolerant isolates, 74 were able to weakly grow at $37^{\circ} \mathrm{C}$. Only 13 psychrotolerant isolates belonging to the genera Rhodopseudomonas (L-1894), Cryobacterium (L-2263 and L-2279), Massilia (L-2271, L-2283, and L-2653), Flavobacterium (L-2291 and L-2562), unidentified Oxalobacteraceae (L-2547), Sphingomonas (L-2552), Pseudomonas (L-2554), Paenibacillus (L-2661), and Streptomyces (N41) were not able to grow at $37^{\circ} \mathrm{C}$.

\section{Hemolysis on Blood Agar Plates}

Two different experiments were performed to observe the hemolytic activity of the isolates. In the first one, the excretion of hemolytically active compounds resulted in either $\alpha$ - or $\beta$-hemolysis around the bacterial colonies on blood agar plates. A $\beta$-hemolytic reaction implies complete lysis of the red blood cells, causing a clear zone on the agar surrounding the colony and it is referred as true hemolysis. On the other hand, an $\alpha$-hemolytic reaction occurs when the hemoglobin in the red blood cells is reduced to methemoglobin, causing a greenish discoloration on the agar surrounding the colonies. Finally, the absence of hemolysis or discoloration is referred to as $\gamma$-hemolysis (Buxton, 2005).

The tested bacterial strains displayed all three phenotypes (Figure 2). Our results showed that the hemolysis was influenced by the incubation temperature (Table 2). Pseudomonas spp. showed psychrotolerant behavior, that is, all of them grew at $15^{\circ} \mathrm{C}$ while only $50 \%$ grew at $37^{\circ} \mathrm{C}$. Of these, $9 / 22$ isolates were $\beta$-hemolytic on both types of blood at $15^{\circ} \mathrm{C}$, whereas only $6 / 22$ were hemolytic at $37^{\circ} \mathrm{C}$. Isolate $\mathrm{L}-2644$ was the only one that expressed $\beta$-hemolysis at both temperatures and on both blood types. No $\alpha$-hemolytic phenotype was observed for this genus (Table 2).

Bacillus spp. exhibited greater temperature range tolerance, with all isolates growing at both 15 and $37^{\circ} \mathrm{C}$. Although $\beta$-hemolytic phenotypes were common at $37^{\circ} \mathrm{C}(11 / 13$ isolates),

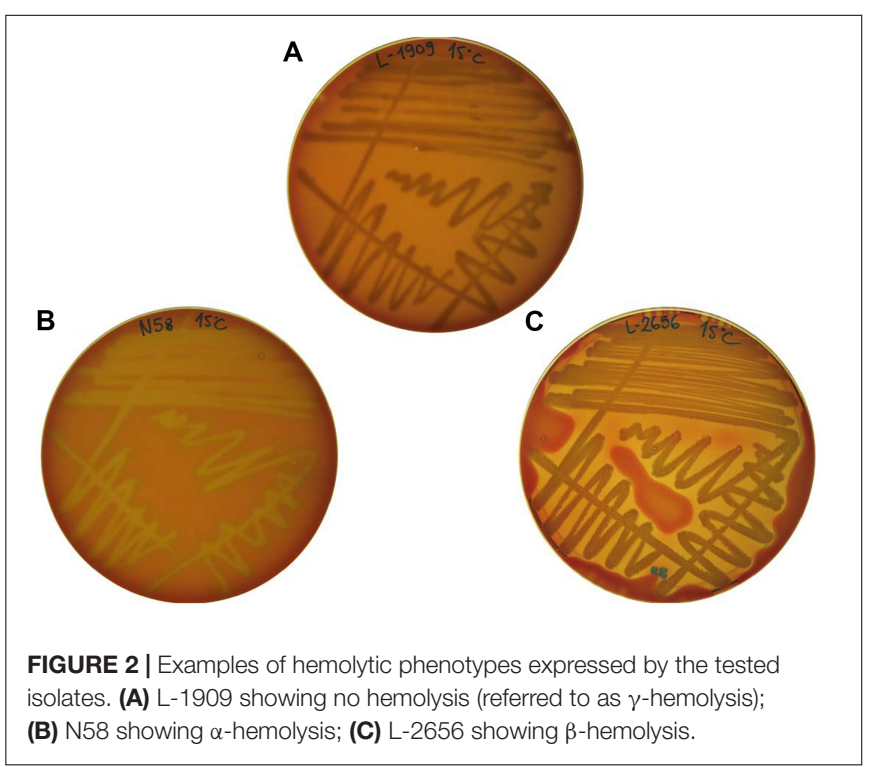


TABLE 2 | List of the bacterial isolates tested for thermotolerance, hemolysis on blood agar at 15 and $37^{\circ} \mathrm{C}$ and resulting hemolytic phenotypes.

\begin{tabular}{|c|c|c|c|c|c|}
\hline \multirow[b]{3}{*}{ Isolate } & \multirow[b]{3}{*}{ Species } & \multicolumn{4}{|c|}{ Phenotype } \\
\hline & & \multicolumn{2}{|c|}{ Bovine blood } & \multicolumn{2}{|c|}{ Sheep blood } \\
\hline & & $15^{\circ} \mathrm{C}$ & $37^{\circ} \mathrm{C}$ & $15^{\circ} \mathrm{C}$ & $37^{\circ} \mathrm{C}$ \\
\hline 12396_bac & Bacillus sp. & $\gamma$ & $\alpha, \beta-$ & $\gamma$ & $\alpha, \beta-$ \\
\hline 12403-Bac & Bacillus sp. & $\gamma$ & $\alpha, \beta-$ & $\gamma$ & $\alpha, \beta-$ \\
\hline L-1896 & Bacillus sp. & $\gamma$ & $\gamma$ & $\gamma$ & $\gamma$ \\
\hline L-1899 & $\begin{array}{l}\text { Cryobacterium } \\
\text { psychrotolerans }\end{array}$ & $\gamma$ & $N G$ & $\gamma$ & $N G$ \\
\hline L-1900 & Sphingomonas sp. & $\gamma$ & $N G$ & $\gamma$ & $N G$ \\
\hline L-1906 & Bacillus sp. & $\gamma$ & $\gamma$ & $\gamma$ & $\gamma$ \\
\hline L-1909 & Arthrobacter sp. & $\gamma$ & $N G$ & $\gamma$ & $N G$ \\
\hline L-1910 & Bacillus sp. & $\gamma$ & $\alpha$ & $\gamma$ & $\alpha$ \\
\hline L-1922 & Micrococcus sp. & $\gamma$ & $\beta$ & $\gamma$ & $\beta$ \\
\hline L-1964 & Pseudomonas sp. & $\beta+$ & $N G$ & $\beta+$ & $N G$ \\
\hline L-1969 & Pedobacter sp. & $\beta$ & $\beta$ & $\beta$ & $\beta$ \\
\hline L-1972 & Sphingomonas sp. & $\gamma$ & $\gamma$ & $\gamma$ & $\gamma$ \\
\hline L-1973 & Pedobacter sp. & $\gamma$ & $\beta$ & $\gamma$ & $\gamma$ \\
\hline L-1980 & Raoultella sp. & $\gamma$ & $\beta$ & $\gamma$ & $\beta$ \\
\hline L-1983 & Pseudomonas sp. & $\gamma$ & $\gamma$ & $\gamma$ & $\gamma$ \\
\hline L-1994 & Flavobacterium sp. & $\beta$ & $\gamma$ & $\beta$ & $\gamma$ \\
\hline L-1995 & Janthinobacterium sp. & $\beta$ & $\beta$ & $\gamma$ & $\beta$ \\
\hline L-2062 & Cryobacterium sp. & $\gamma$ & $\gamma$ & $\gamma$ & $\gamma$ \\
\hline L-2063 & Undibacterium sp. & $\gamma$ & $N G$ & $\gamma$ & $\gamma$ \\
\hline L-2137 & Pseudomonas sp. & $\beta-$ & $\beta-$ & $\gamma$ & $\gamma$ \\
\hline L-2142 & Pseudomonas sp. & $\gamma$ & $\beta-$ & $\gamma$ & $\gamma$ \\
\hline$L-2145$ & Pseudomonas sp. & $\gamma$ & $\beta-$ & $\gamma$ & $\gamma$ \\
\hline L-2265 & Pseudomonas sp. & $\gamma$ & $\beta-$ & $\gamma$ & $\gamma$ \\
\hline L-2266 & Janthinobacterium sp. & $\gamma$ & $\beta-$ & $\gamma$ & $\gamma$ \\
\hline L-2267 & Undibacterium sp. & $N G$ & $N G$ & $N G$ & $N G$ \\
\hline L-2270 & $\begin{array}{l}\text { Unidentified } \\
\text { Oxalobacteraceae }\end{array}$ & $N G$ & $N G$ & $N G$ & $N G$ \\
\hline L-2271 & Massilia sp. & $N G$ & $N G$ & $N G$ & $N G$ \\
\hline L-2273 & Sphingomonas sp. & $N G$ & $N G$ & $N G$ & $N G$ \\
\hline$L-2275$ & Massilia sp. & $N G$ & $N G$ & $N G$ & $N G$ \\
\hline L-2276 & Massilia sp. & $N G$ & $N G$ & $N G$ & $N G$ \\
\hline$L-2279$ & Cryobacterium sp. & $\gamma$ & $\alpha$ & $\gamma$ & $N G$ \\
\hline L-2285 & Cryobacterium sp. & $\beta-$ & $\beta-$ & $\gamma$ & $\gamma$ \\
\hline L-2290 & Herminiimonas sp. & $N G$ & $N G$ & $N G$ & $N G$ \\
\hline L-2291 & Flavobacterium sp. & $N G$ & $N G$ & $N G$ & $N G$ \\
\hline$L-2430$ & Frigoribacterium sp. & $\gamma$ & $\beta$ & $\gamma$ & $\beta$ \\
\hline L-2433 & Curtobacterium sp. & $\beta+$ & $N G$ & $\beta$ & $N G$ \\
\hline L-2552 & Sphingomonas sp. & $\gamma$ & $N G$ & $\gamma$ & $N G$ \\
\hline L-2553 & $\begin{array}{l}\text { Pseudomonas } \\
\text { graminis }\end{array}$ & $\gamma$ & $N G$ & $\gamma$ & $N G$ \\
\hline$L-2554$ & Pseudomonas sp. & $\gamma$ & $N G$ & $\gamma$ & $N G$ \\
\hline L-2558 & Polaromonas sp. & $\gamma$ & $N G$ & $\gamma$ & $N G$ \\
\hline L-2560 & Flavobacterium sp. & $\gamma$ & $N G$ & $\gamma$ & $N G$ \\
\hline L-2571 & Cryobacterium sp. & $\beta-$ & $\beta$ & $\gamma$ & $\beta$ \\
\hline L-2573 & Flavobacterium sp. & $N G$ & $N G$ & $N G$ & $N G$ \\
\hline L-2575 & Pseudomonas sp. & $\gamma$ & $N G$ & $\gamma$ & $N G$ \\
\hline L-2577 & Massilia sp. & $N G$ & $N G$ & $N G$ & $N G$ \\
\hline L-2578 & Pseudomonas sp. & $\gamma$ & $\gamma$ & $\gamma$ & $\gamma$ \\
\hline L-2580 & Cryobacterium sp. & $\gamma$ & $\beta$ & $\gamma$ & $\beta$ \\
\hline$L-2643$ & Pseudomonas sp. & $\beta-$ & $\gamma$ & $\gamma$ & $\gamma$ \\
\hline
\end{tabular}

TABLE 2 | Continued

\begin{tabular}{|c|c|c|c|c|c|}
\hline \multirow[b]{3}{*}{ Isolate } & \multirow[b]{3}{*}{ Species } & \multicolumn{4}{|c|}{ Phenotype } \\
\hline & & \multicolumn{2}{|c|}{ Bovine blood } & \multicolumn{2}{|c|}{ Sheep blood } \\
\hline & & $15^{\circ} \mathrm{C}$ & $37^{\circ} \mathrm{C}$ & $15^{\circ} \mathrm{C}$ & $37^{\circ} \mathrm{C}$ \\
\hline L-2644 & $\begin{array}{l}\text { Pseudomonas } \\
\text { fluorescens }\end{array}$ & $\beta+$ & $\beta-$ & $\beta+$ & $\beta-$ \\
\hline L-2646 & $\begin{array}{l}\text { Pseudomonas } \\
\text { graminis }\end{array}$ & $\gamma$ & $\gamma$ & $\gamma$ & $\gamma$ \\
\hline L-2649 & $\begin{array}{l}\text { Sphingomonas sp. } \\
\text { (glacialis) }\end{array}$ & $\gamma$ & $N G$ & $\gamma$ & $N G$ \\
\hline L-2650 & Pseudomonas sp. & $\beta+$ & $N G$ & $\beta+$ & $N G$ \\
\hline L-2652 & $\begin{array}{l}\text { Pseudomonas } \\
\text { frederiksbergensis }\end{array}$ & $\gamma$ & $\gamma$ & $\gamma$ & $\beta$ \\
\hline L-2653 & Massilia sp. & $\gamma$ & $N G$ & $\gamma$ & $N G$ \\
\hline L-2656 & $\begin{array}{l}\text { Pseudomonas } \\
\text { fluorescens }\end{array}$ & $\beta+$ & $\beta$ & $\beta$ & $\gamma$ \\
\hline L-2657 & Pseudomonas sp. & $\beta+$ & $N G$ & $\beta$ & $\beta$ \\
\hline L-2658 & $\begin{array}{l}\text { Pseudomonas } \\
\text { fluorescens }\end{array}$ & $\beta+$ & $N G$ & $\beta$ & $N G$ \\
\hline L-2659 & Pseudomonas sp. & $\beta+$ & $N G$ & $\beta+$ & $N G$ \\
\hline L-2694 & Sphingomonas sp. & $\gamma$ & $\beta$ & $\gamma$ & $\alpha-$ \\
\hline L-2696 & Pseudomonas sp. & $\beta-$ & $\gamma$ & $\gamma$ & $\beta$ \\
\hline An34 & Leifsonia sp. & $\gamma$ & $\alpha-$ & $\gamma$ & $\alpha-$ \\
\hline An58 & Enterococcus sp. & $\gamma$ & $\alpha-$ & $\alpha$ & $\gamma$ \\
\hline S3 & Micromonospora sp. & $\gamma$ & $\beta$ & $\gamma$ & $\beta$ \\
\hline S7 & Bacillus sp. & $\beta$ & $\beta$ & $\beta$ & $\beta$ \\
\hline S8 & Microbacterium sp. & $\gamma$ & $\alpha-$ & $\gamma$ & $\alpha-$ \\
\hline S10 & Oerskovia sp. & $\alpha$ & $\alpha$ & $\alpha$ & $\beta$ \\
\hline S23b & Microbacterium sp. & $\gamma$ & $\alpha$ & $\gamma$ & $\beta$ \\
\hline S24 & Brevibacterium sp. & $\gamma$ & $\beta-$ & $\gamma$ & $\alpha$ \\
\hline S26 & Microbacterium sp. & $\gamma$ & $\alpha$ & $\alpha$ & $\alpha$ \\
\hline S27b & Carnobacterium sp. & $\alpha$ & $\alpha-$ & $\alpha$ & $\gamma$ \\
\hline S32 & Tessaracoccus sp. & $\gamma$ & $\alpha$ & $\alpha-$ & $\alpha$ \\
\hline S44 & Bacillus sp. & $\gamma$ & $\beta+$ & $\gamma$ & $\beta+$ \\
\hline S58 & Salinibacterium sp. & $\gamma$ & $\alpha-$ & $\gamma$ & $\alpha$ \\
\hline S60 & Microbacterium sp. & $\gamma$ & $\alpha-$ & $\gamma$ & $\alpha$ \\
\hline S70 & Bacillus sp. & $\gamma$ & $\alpha$ & $\gamma$ & $\alpha$ \\
\hline S71 & Bacillus sp. & $\gamma$ & $\alpha-$ & $\gamma$ & $\beta$ \\
\hline N2 & Exiguobacterium sp. & $\gamma$ & $\alpha-$ & $\gamma$ & $\alpha-$ \\
\hline N7 & Paenibacillus sp. & $\gamma$ & $\gamma$ & $\gamma$ & $\gamma$ \\
\hline N18 & Micromonospora sp. & $\beta$ & $\beta+$ & $\beta$ & $\beta$ \\
\hline N23 & Bacillus sp. & $\gamma$ & $\beta+$ & $\gamma$ & $\beta+$ \\
\hline N24 & Bacillus sp. & $\gamma$ & $\beta+$ & $\gamma$ & $\beta+$ \\
\hline N28 & Streptomyces sp. & $\beta-$ & $\gamma$ & $\beta+$ & $\beta$ \\
\hline N34 & Bacillus sp. & $\beta$ & $\beta+$ & $\beta-$ & $\beta$ \\
\hline N36a & Pedobacter sp. & $\alpha$ & $\alpha$ & $\beta+$ & $\alpha$ \\
\hline N39 & Carnobacterium sp. & $\alpha$ & $\beta$ & $\alpha$ & $\gamma$ \\
\hline $\mathrm{N} 40$ & Pseudomonas sp. & $\beta+$ & $N G$ & $\beta$ & $N G$ \\
\hline N41 & Streptomyces sp. & $\gamma$ & $N G$ & $\gamma$ & $N G$ \\
\hline N42 & Streptomyces sp. & $\alpha$ & $\beta$ & $\gamma$ & $\beta$ \\
\hline N54 & Psychrobacillus sp. & $\gamma$ & $\gamma$ & $\gamma$ & $\gamma$ \\
\hline N58 & Carnobacterium sp. & $\alpha+$ & $N G$ & $\alpha+$ & $N G$ \\
\hline N61 & Psychrobacter sp. & $\gamma$ & $N G$ & $\gamma$ & $N G$ \\
\hline N71 & Pseudomonas sp. & $\beta+$ & $N G$ & $\beta+$ & $N G$ \\
\hline N83 & Bacillus sp. & $\gamma$ & $\beta$ & $\gamma$ & $\beta$ \\
\hline N106 & Salinibacterium sp. & $\gamma$ & $\alpha-$ & $\gamma$ & $\alpha-$ \\
\hline
\end{tabular}

Hemolytic phenotypes: $\alpha, \alpha$-hemolytic; $\beta, \beta$-hemolytic; $\gamma$, non-hemolytic; + , signifies a stronger phenotype; -, signifies a weaker phenotype; NG, no growth. 
at the lower temperature the phenotypes were mostly nonhemolytic. Two isolates, S7 and N34, expressed $\beta$-hemolysis at both temperatures and on both blood types. Of the Micromonospora spp., strain N18 presented $\beta$-hemolytic activity at both temperatures and blood types, while strain S3 was $\beta$-hemolytic only at $37^{\circ} \mathrm{C}$ in both blood types. Isolates of Carnobacterium spp. displayed the strongest $\alpha$ hemolysis of all the tested bacteria (Figure 2B). Interestingly, isolates L1994 (Flavobacterium sp.) and L-1995, (Janthinobacterium sp.), obtained from tap water from Svalbard, that also showed $\beta$-hemolytic activity and the only isolate belonging to the Enterobacteriaceae family (L-1980, Raoultella sp.) displayed a $\beta$-hemolytic activity at $37^{\circ} \mathrm{C}$, whereas they were non-hemolytic at $15^{\circ} \mathrm{C}$.

In general, isolates that were non-hemolytic on bovine blood plates were also non-hemolytic on sheep blood plates (Table 2) except for Pseudomonas spp. L-2652 ( $\beta$-hemolytic only on sheep blood at $\left.37^{\circ} \mathrm{C}\right)$ and $\mathrm{L}-2696\left(\beta\right.$-hemolytic at $15^{\circ} \mathrm{C}$ on bovine blood and at $37^{\circ} \mathrm{C}$ on sheep blood), Enterococcus sp. An58 ( $\alpha$-hemolytic at $37^{\circ} \mathrm{C}$ on bovine and at $15^{\circ} \mathrm{C}$ on sheep blood), and Pedobacter sp. N36a ( $\beta$-hemolytic at $15^{\circ} \mathrm{C}$ on sheep blood but $\alpha$-hemolytic at $37^{\circ} \mathrm{C}$ and at both temperatures on bovine blood). About $30 \%$ of the isolates showed non-hemolytic phenotypes on both blood types, e.g., Sphingomonas sp., Psychrobacillus sp. Species belonging to the genera Herminiimonas sp. and Massilia sp. did not grow at any temperature or blood type used in this experiment. The three control strains displayed their corresponding hemolytic phenotype on blood agar plates.

\section{Hemolytic Assay With Erythrocyte Suspension}

The second experiment involved the observation of hemolytic activity of the ethanolic extracts of bacterial lysates in a short assay (within a 60-min time frame) using erythrocyte suspensions. The objective of this experiment was to determine the potential presence of membrane-active secondary metabolites which could be present in the tested bacteria, and which could contribute to the pathogenicity of the producing organism.

In the assays with bovine and sheep erythrocytes in suspension, only 5 extracts in total were hemolytic within 60 min of the assay: Pseudomonas sp. L-2644, L-2656, and L2657 together with Micromonospora sp. S3 and N18 (Figure 3 and Supplementary Figure S1). Pseudomonas spp. showed faster hemolytic reactions on both blood types, compared to Micromonospora sp. In general, for the Pseudomonas sp. extracts higher values of $1 / t_{50}$ were observed in bovine blood compared to sheep blood (Figure 3). Ethanolic extracts of the three control species displaying the hemolytic phenotype on blood agar plates were inactive on erythrocytes in suspension.

\section{Antimicrobial Susceptibility Test}

In total, 118 isolates were tested for antimicrobial resistance. The plates were read as soon as colonies were detected on them and the results are presented in Table 3 (summary) and Supplementary Table S3 (all results), except for 14 isolates that did not grow on the used media or in the presence of any of the antimicrobials tested. TET was the most effective antimicrobial, with most isolates (95/104) being susceptible, followed by KAN (84/104 susceptible isolates). At the other end of the spectrum, IPM was the least effective antimicrobial at the used concentration, with only 21/104 susceptible isolates. Resistant strains to higher concentrations of imipenem are mostly from the genera Flavobacterium, Enterococcus, Janthinobacterium, Raoultella, and, notably, Pseudomonas. Interestingly, not all Pseudomonas spp. behave alike. For instance, strains L-2652 (closely related to $P$. frederiksbergensis) and L-2553 and L2646 (both closely related to $P$. graminis) were not resistant to $>4 \mathrm{~m} / \mathrm{L}$ of imipenem in the media. The following IPM-resistant strains were also carbapenemase producers (OXA-48 and other carbapenemases such as KPC, MBL, or NDM): Flavobacterium sp. (L-1994), Janthinobacterium sp. L-1995, Pseudomonas sp. N71 (L-5704), L-1983, L-2137, L-2142, L-2145, L-2554, L-2265, L-2575, L-2578, L2643, L-2644, L2650, L-2656, L-2658, and Raoultella sp. L-1980 (Supplementary Table S4).
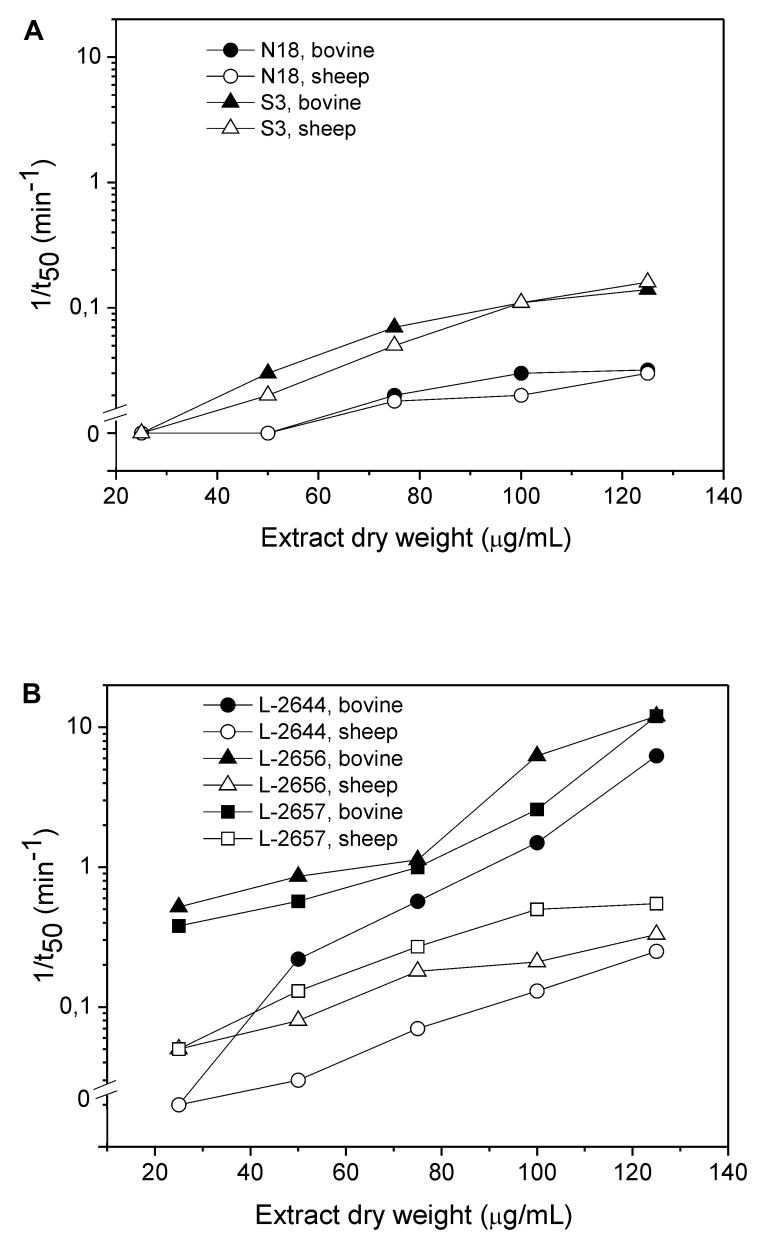

FIGURE 3 | Hemolytic activity of ethanolic extracts of Micromonospora sp. (A) and Pseudomonas sp. (B). Dependence of the rate of hemolysis, $1 / t_{50}$, on the dry extract concentration. The hemolytic activity was assayed against bovine (full symbols) and sheep (open symbols) erythrocytes. 
TABLE 3 | Summary of results for antimicrobial susceptibility for the 104 isolates tested, showing number of isolates that are: - susceptible; (-) moderately susceptible; (+) moderately resistant; + resistant; $\mathrm{M}$ indicates the appearance of individual mutant colonies.

\begin{tabular}{|c|c|c|c|c|c|c|c|c|c|}
\hline Summary & Growth & AMP & $\mathrm{CHL}$ & CIP & CTX & ERY & IPM & KAN & TET \\
\hline- & 17 & 74 & 77 & 47 & 41 & 64 & 21 & 84 & 95 \\
\hline$(-)$ & 9 & 2 & 4 & 11 & 9 & 6 & 13 & 9 & 7 \\
\hline$(+)$ & 11 & 1 & 1 & 5 & 5 & 7 & 9 & 4 & 0 \\
\hline+ & 67 & 27 & 22 & 17 & 49 & 27 & 61 & 6 & 2 \\
\hline$M$ & 0 & 0 & 0 & 24 & 0 & 0 & 0 & 1 & 0 \\
\hline
\end{tabular}

After a week of incubation, resistant colonies (possible mutants) appeared only on plates containing CIP (24/104) and $\operatorname{KAN}(1 / 104)$. About $50 \%$ of the isolates (54/104) were resistant to CTX.

The species that were resistant to TET belonged to five genera only: Pseudomonas (L-1964, L-1983, L-2137, L-2142, and L-2643), Janthinobacterium (L-1995), Oerskovia (S10), Flavobacterium (L1994), and Rahnella (L-2695). The isolates mentioned above (of which two were obtained from tap water), shared very similar antimicrobial resistance profiles, i.e., resistance to all antimicrobials tested except for KAN and individual mutant colonies for CIP.

All Pseudomonas sp. were resistant to multiple antimicrobials, including AMP, CHL, CTX, ERY, and IPM. However, the two isolates belonging to Pseudomonas graminis were susceptible to AMP, CHL, CIP, ERY, KAN, and TET. The majority (18/24) of individual mutant colonies were also observed among the Pseudomonas spp. isolates.

Generally, Bacillus spp. were susceptible to the majority of the antimicrobials tested (AMP, CHL, ERY, KAN, and TET), with a few exceptions in case of CIP, IPM, and CTX. Micromonospora spp. were predominantly susceptible to the antimicrobials tested, with resistance detected for CTX and ERY.

Isolates belonging to the Enterobacteriaceae family (i.e., Rahnella sp. L-2695 and Raoultella sp. L-1980) were resistant to AMP and IPM. Some isolates of the genera Cryobacterium (L-2062, L-2285, L-2571, and L-2580), Massilia (L-2271) and Undibacterium (L-2063 and L-2267), did not show growth on the control plates (nutrient agar without added antimicrobials) but generally showed better growth on the plates containing IPM.

\section{DISCUSSION}

Until recently, the Arctic represented a pristine environment, largely unaffected by anthropogenic influences. However, this geographic area is now experiencing the dramatic repercussions of climate change more than other regions on the planet (Intergovernmental Panel on Climate Change [IPCC], 2007). Due to its low adaptability, these consequences are amplified (Doney et al., 2012) and the stressful conditions they bring about might cause the release of environmental bacteria with potential virulence-associated phenotypes, e.g., compounds with hemolytic activity and antimicrobial resistance. Moreover, bacterial species in the short term are expected to come in contact more frequently with humans, animals, and plants outside of their current environments (Epstein, 2001; Cavicchioli et al., 2019; Hutchins et al., 2019).

\section{Majority of Psychrotolerant Bacterial Isolates Are Able to Grow at $37^{\circ} \mathrm{C}$}

In this study, more than $70 \%$ of the culturable species obtained from the Arctic environmental samples were psychrotolerant, with an optimal growth temperature of about $15^{\circ} \mathrm{C}$. Although a growth temperature range of $8-20^{\circ} \mathrm{C}$ (Moyer and Morita, 2007) should define psychrotolerant microorganisms, the majority of our psychrotolerant strains were able to grow at $37^{\circ} \mathrm{C}$, indicating a broader range of temperature adaptation (Tindall, 2004). Interestingly, the 13 isolates obtained from incubation at 15$17^{\circ} \mathrm{C}$ that were not able to grow at $37^{\circ} \mathrm{C}$ might be considered as true psychrotolerants or true psychrophiles with slower growth rates at higher temperature, and a broader temperature growth range (Tindall, 2004; Moyer and Morita, 2007).

\section{Environmental Strains Produce Compounds With Hemolytic Activity Expressed Differently at Low $\left(15^{\circ} \mathrm{C}\right)$ and High $\left(37^{\circ} \mathrm{C}\right)$ Temperatures}

A considerable number of isolates in this study showed a hemolytic phenotype when cultured on blood agar plates, in accordance to recent reports (Mogrovejo-Arias et al., 2020). The type of blood used (bovine vs. sheep) did not affect hemolytic activity. Both $\alpha$ - and $\beta$-hemolytic phenotypes are considered as a virulence-associated determinant and of clinical relevance when assessing the significance of the hemolytic environmental species and/or strains (Bayley, 1997; Ramachandran, 2013).

While most of the bacterial isolates cultured on agar plates showed active growth, some genera (Flavobacterium sp., Herminiimonas sp., Massilia sp., Sphingomonas sp., and Undibacterium sp.) could not be assessed due to lack of growth, which was possibly inhibited by the high nutrient content of the culture medium used for this test (Tindall, 2004). In addition to an incubation temperature of $15^{\circ} \mathrm{C}$, a suitable temperature for the growth of psychrotolerant bacteria, the blood agar plates were also incubated at $37^{\circ} \mathrm{C}$ in order to assess the hemolysis at a clinically relevant temperature and to investigate the influence of the temperature on the hemolysis activity. Several genera responded differently to the incubation temperature. For instance, Pseudomonas spp. had mostly hemolytic phenotypes at $15^{\circ} \mathrm{C}$ while Bacillus spp. expressed hemolytic activity mainly at $37^{\circ} \mathrm{C}$. Differences in the hemolysins structures and modes 
of action might explain that some of them have a lytic effect only above certain temperatures, at which the characteristics of erythrocyte membranes change due to increased membrane fluidity (Carr et al., 2001; Asam et al., 2015). Alternatively, the expression of hemolytic genes might be temperature-regulated (as described by Madrid et al., 2002) and could account for the differences observed in our experiments.

\section{Pseudomonas sp. Organic Extracts Show Faster Hemolytic Response in Bovine Erythrocytes Suspension Than in Sheep Erythrocytes Within $\mathbf{6 0}$ min}

Our study comprises a large and preliminary screening study of crude extracts where non-purified membrane-active compounds were present. To the best of our knowledge, it represents the first screening of this sort for hemolytic activity in Arctic environmental bacteria. The hemolytic activity of ethanolic extracts was tested in two types of erythrocyte suspensions: sheep and bovine. Sheep blood is commonly used as a standard for the determination of the hemolytic phenotype (Yeh et al., 2009; Atlas, 2010) and bovine erythrocytes have been previously used to determine the hemolytic capabilities of environmental extracts from different habitats and organisms (Sepčić et al., 2011).

The hemolytic potential of human-associated, pathogenic or opportunistic bacteria is regularly assessed using animal blood (Bevivino et al., 2002; González-Rodríguez et al., 2007) as it is suitable for carrying out microbiological tests used in routine identification and susceptibility profiling of known human pathogens (Yeh et al., 2009).

Anuclear, mature red blood cells are often used as a model to assess the membrane damage, either by monitoring the hemoglobin release or by measuring the turbidity of erythrocyte suspension. However, it should not be inferred that erythrocytes are the only target cells of the compounds observed in this study (Tomita and Kamio, 1997) given that hemolytic compounds can often also be cytolytic for cells of the immune system, e.g., macrophages and neutrophils (Asam et al., 2015), which, in the case of pathogenic organisms, greatly increases their potential virulence (Billington et al., 2000).

The discrepancies in membrane composition among different mammalian erythrocytes influence the hemolytic activity of hemolysins, which act by recognizing specific membrane lipids or membrane receptors (DuMont and Torres, 2014; Rojko and Anderluh, 2015). We observed that the lytic activity of the tested Pseudomonas sp. extracts was more pronounced on bovine erythrocytes than on the sheep ones (Figure 3). Red blood cell membranes from different mammals display different composition and physical characteristics (e.g., fluidity). Sheep erythrocytes contain a higher percentage of choline phospholipids (with sphingomyelin representing more than $50 \%$ of all the phospholipids) and acidic phospholipids, but a lower content of phosphatidylethanolamine compared to bovine erythrocytes (Bernheimer, 1974; Virtanen et al., 1998; Windberger et al., 2003). Cholesterol content, on the other hand, is higher in bovine red blood cells than in sheep ones (Nelson, 1967). Thus, the faster hemolytic reaction on bovine erythrocytes observed might be because the hemolytic compound(s) produced by the isolates in this study have greater affinity for cholesterolenriched membrane domains.

Based on our results, the use of more than one type of blood is recommended as it widens the spectrum of observed hemolytic activities. Future research could benefit from the inclusion of assays with human blood, the results of which could be predicted to some extend based on similarities with the types of blood used in the present study.

\section{Blood Agar and Turbidimetric Assays Highlight Different Compounds Responsible for Hemolysis}

A greater number of isolates were found to have hemolytic activity on blood agar plates (around 30 isolates) vs. the activity of their ethanolic extracts on erythrocyte suspensions (5 isolates).

The culture conditions at which the isolates were grown in preparation for each test, i.e., solid media in agar plates vs. liquid media used for the suspension test, could account for the difference in the number of positive phenotypes as they directly affect gene expression (Favero et al., 2014).

Another possible explanation for such a remarkable difference between the tests is that each one assesses the presence of different compounds. Plates show the effects of a wider range of molecules produced by the bacteria in the course of their growth (e.g., proteinaceous endotoxins, exotoxins, pigments, and secondary metabolites). On the other hand, for the suspensions test, a limited selection of compounds was obtained in the extraction solvent (96\% ethanol in this case). Ethanol allows the extraction of small, less polar molecules or secondary metabolites and likely excludes proteins (Sepčić et al., 2011). Crude extracts, moreover, might possess more than one hemolytically active and less polar compound, mainly acting as surfactants and whose function is independent of membrane lipid composition. This might explain the observed absence of hemolytic activity of the ethanolic extract of $S$. pyogenes, a bacterium commonly used as a positive $\beta$-hemolytic control in blood agar tests. In fact, the main hemolytic compounds characteristic of $S$. pyogenes are pore-forming proteinaceous cytotoxins streptolysin $\mathrm{O}$ and streptolysin S (Hynes and Sloan, 2016), which cannot be extracted with ethanol.

Finally, the growth phase of the culture at the moment of the test might vary, directly affecting the compounds produced by the bacteria. That is, compounds produced in actively growing cultures (for instance, liquid cultures) differ from those produced in cultures going through stationary phase (for instance, solid cultures).

\section{Arctic Environmental Strains Show Widespread Resistance to Commercial Antimicrobials}

Studying antimicrobial resistance profiles in Arctic isolates is gaining in importance since climate change is exerting a stronger pressure on this environment and higher temperatures are associated with increased antimicrobial resistance in common pathogens (Hutchins et al., 2019). 
No breakpoint tables for Minimum Inhibitory Concentration or Zone Diameters have been established for Arctic species/strains (European Committee on Antimicrobial Susceptibility Testing [EUCAST], 2019). Therefore, the definition of resistance for these bacteria is difficult to ascertain. In this study, we performed screening for phenotypic resistance on media supplemented with antimicrobials as an indicator for the presence of resistance genes.

On one hand, we observed that a majority of the Arctic environmental isolates analyzed were resistant to at least one of the antimicrobials tested, suggesting a strong competitiveness in the habitat. Some isolates were resistant even toward broad-spectrum antimicrobials, such as ciprofloxacin and chloramphenicol. Similar results were found in other natural environments such as Antarctica (Tam et al., 2015), highaltitude wetlands in Argentina (Dib et al., 2008), and Siberia (Mindlin et al., 2008). On the other hand, almost all of the isolates were susceptible to tetracycline, contrary to what has been reported before for other cold environments (Perron et al., 2015). Since tetracycline could be naturally occurring in soils, such widespread susceptibility is surprising, but could be due to a lack of tetracycline producers in the Arctic. In accordance to our findings, Pal et al. (2016) reported that tetracycline resistance dominates human, human-impacted and animal microbiomes but not so far natural environments. The mutant phenotypes observed for ciprofloxacin are usually induced by low concentrations of this antimicrobial (Cirz and Romesberg, 2006).

Resistance to some antibiotics can occur quickly during selective enrichment, predominantly that which is triggered by point mutations in housekeeping genes, e.g., ribosomal proteins and efflux pumps. Accordingly, growth observed in plates containing ciprofloxacin, erythromycin, and kanamycin has been cautiously interpreted. The constant appearance of a low number of individual, presumably mutant, colonies is indicated in Supplementary Table S3.

Isolates belonging to the genus Pseudomonas were the ones with the strongest multidrug-resistant abilities, showing marked resistance tetracycline, and with frequent occurrence of individual mutant ciprofloxacin resistant colonies. Correspondingly, Pseudomonas spp. isolated from Antarctica showed a variety of antimicrobial resistant profiles (Tam et al., 2015). Pseudomonas sp. are known for its extended resistances to antimicrobials (European Committee on Antimicrobial Susceptibility Testing [EUCAST], 2019) and are known to possess capsules that might aid in lowering the concentration of antimicrobial that reaches the cells. In addition, Pseudomonas sp. possess efflux pumps which contribute to the multidrug resistance phenotype and might explain the mutant phenotypes observed (Okamoto et al., 2002; Aeschlimann, 2003). Even though efflux pumps can be also associated with other functions in the cell, the responsible genes can be transferred to other environments and into other species where the resistance phenotype becomes of clinical relevance (Graham et al., 2019).

Resistance to cefotaxime was observed in $50 \%$ of our isolates. Resistant phenotypes against this extended-spectrum $\beta$-lactam is considered of clinical relevance (Mir et al., 2016), especially among Gram-negative species and notoriously resistant Pseudomonas sp.

Finally, we observed that the concentration of imipenem used in this study favored, rather than inhibited, the growth of several isolates, notably Massilia sp. and Cryobacterium sp. As far as we can tell from searching the available literature, such observation hasn't been reported yet. Phenotypic resistance to imipenem is of high importance since carbapenemase-producing bacteria have become a major public health concern worldwide. In this study, we identified carbapenem resistant bacteria and predicted carbapenem resistance mechanisms (CRM) and the subsequent potential for horizontal spread. While the best known and currently most important CRM have been described in members of the Enterobacteriaceae family and for Pseudomonas aeruginosa, literature data about CRM in Grampositive bacteria is scarce.

We have observed a variety of resistotypes for carbapenem resistance (CR) among several, but not all, Bacillus sp. isolates. Further, we retrieved CR isolates from the genera Cryobacterium, Leifsonia, and Streptomyces. This observation, in accordance with CR in Gram-positive bacteria, is likely the result of substitutions in amino acid sequences of penicillin-binding proteins (PBPs) or acquisition/production of new carbapenem-resistant PBPs (Papp-Wallace et al., 2011). Although chromosomally encoded, these alleles could spread horizontally by transformation or transduction.

Acquired carbapenem resistance in Gram-negative bacteria is a consequence of enzymatic inactivation of the drug, target site mutation and efflux pumps (Codjoe and Donkor, 2018). We hypothesize on putative resistance mechanisms on the basis of the most commonly described mechanism for strains of the same species/genus or other closely related bacteria, and our results of differential growth on nutrient agar plates supplemented with different concentrations of imipenem and commercial CHROMID ${ }^{\circledR}$ CARBA SMART agar plates. The majority of carbapenem resistant Pseudomonas isolates grew in plates containing 4-10 mg/L of imipenem and on both sections of the CARBA SMART plates. This indicates the presence of putative carbapenemase enzymes. Pseudomonas sp. L-2696, grew on nutrient agar plates with $10 \mathrm{mg} / \mathrm{L}$ of imipenem but not on CARBA SMART plates, indicating putative efflux pumps and/or target site mutation. Further studies, including cloning, would clarify the possibility and subsequent threat of horizontal transfer to clinically important Pseudomonas strains. Flavobacterium sp. L-1994 grew on both CARBA SMART sections, thus possibly encoding a carbapenemase. Naas et al. (2003) described the JOHN-1 $\beta$ - metallo- $\beta$-lactamase from an Flavobacterium johnsoniae, an environmental plant pathogen which can also cause skin lesions in fish (Naas et al., 2003) and Kuai et al. (2011) described a KPC-2 enzyme from a Flavobacterium odoratum strain (Kuai et al., 2011). Carbapenemase genes have also been described from other members of the Flavobacteriaceae family, such as the chromosome-encoded metallo- $\beta$-lactamases MUS-1 and MUS-2 in Myroides and carbapenemases from Chryseobacterium strains (Al-Bayssari et al., 2015; Gudeta et al., 2016). Janthinobacterium sp. L-1995 grew on nutrient agar plates with imipenem at concentrations up to $4 \mathrm{mg} / \mathrm{L}$ and on both 
media on CARBA SMART plates. Carbapenem resistance in member of this genus has been described by Rossolini et al. (2001) and also observed by Gudeta et al. (2016). The described carbapenemases were chromosomally encoded and not proven yet to be horizontally transferable. The most interesting isolates, given the relatedness to carbapenem resistant Enterobacteriaceae are Rahnella sp. L-2695 and Raoultella ornithinolytica L-1980. The former was negative for carbapenemase and positive for OXA-48-like hydrolytic activity and the later was positive for both. Besides the fact, that the presence of carbapenemases genes has been confirmed several times for Raoultella spp. a large plasmid carrying genes for NDM-1- and CTX-M-3 $\beta$-lactamases, has been detected in a carbapenemase-producing $R$. ornithinolytica strain from stool samples recently (Wang et al., 2019). Particularly interesting is the Rahnella sp. isolate L-2695, since it is, in addition to showing OXA-48-like carbapenemase activity, one of only two tetracycline resistant isolates. Integrons and chromosomal extended-spectrum class A $\beta$-lactamase have already been described in members of this genus (Ruimy et al., 2010; Koczura et al., 2016). To summarize; we predict chromosome encoded $\beta$-lactamases for the majority of the isolated imipenem resistant strains. According to literature data, the presence of plasmid or phage encoded resistance genes is less likely. Nevertheless, horizontal transfer events of resistance genes is a possible event, predominantly through transduction by phages.

\section{CONCLUSION}

To the best of our knowledge, this study is among the first screenings of Arctic environmental bacteria for hemolytic activity, a common bacterial virulence-associated phenotype, in extreme habitats. Hemolytic activity was temperature-dependent and observed in a third of the tested isolates on blood agar plates with both sheep and bovine blood types. In erythrocyte suspensions, the hemolysis occurred only in five isolates belonging to genera Pseudomonas and Micromonospora. The type of erythrocytes appears to influence the reaction time for the hemolytic compounds, as bovine blood was more readily lysed than sheep blood with Pseudomonas sp. extracts. In addition, the Arctic strains tested showed resistance to several commonly used and clinically relevant antimicrobials. However, the number of kanamycin and tetracycline resistant strains was rather low. Imipenem was the antimicrobial with most resistant isolates, possibly due to the low concentration tested or the widespread presence of chromosome encoded

\section{REFERENCES}

Aeschlimann, J. R. (2003). The role of multidrug efflux pumps in the antibiotic resistance of Pseudomonas aeruginosa and other gram-negative bacteria. Pharmacotherary 23, 916-924. doi: 10.1592/phco.23.7.916.3 2722

Agnew, A., Wang, J., Fanning, S., Bearhop, S., and Mcmahon, B. J. (2016). Insights into antimicrobial resistance among long distance migratory East Canadian High Arctic light-bellied Brent geese (Branta bernicla hrota). Ir. Vet. J. 69:13. doi: 10.1186/s13620-016-0072-7 $\beta$-lactamases. In the context of our study, Pseudomonas was the genus with the highest potential clinical relevance: hemolytic on blood agar plates, hemolytic on erythrocyte suspensions and with a broad resistance profile to the antimicrobials tested. Studying potential pathogenic phenotypes of environmental strains provides insights into possible evolutionary adaptations and origins of clinically relevant bacteria and helps assessing the possible threats Arctic bacteria represent in other environments.

\section{DATA AVAILABILITY STATEMENT}

The datasets generated for this study can be found in GenBank with the following accession numbers: MK453054-MK453127, MK670504-MK670553, MN161207-MN161227, MH714605MH714685, and MN450679-MN450730.

\section{AUTHOR CONTRIBUTIONS}

DM and LP collected the samples, performed the wet lab analyses, interpreted the data, and wrote the manuscript with input from all co-authors. CG, MT, JA-A, and KS designed and guided the execution of all experiments. MT and JA-A performed additional experiments with the imipenem-resistant strains. FB and NG-C supervised the project and contributed to the interpretation of the results and valuable discussion.

\section{FUNDING}

This project has received funding from the European Union's Horizon 2020 Research and Innovation Programme under the Marie Skłodowska-Curie grant agreement no. 675546. We acknowledge the financial support from the Slovenian Research Agency to the Infrastructural Centre Mycosmo (MRIC UL) and to the programs P1-0170 and P1-0207. We further acknowledge support from the United Kingdom Natural Environment Research Council Consortium Grant 'Black and Bloom' (NE/M021025/1).

\section{SUPPLEMENTARY MATERIAL}

The Supplementary Material for this article can be found online at: https://www.frontiersin.org/articles/10.3389/fmicb. 2020.00570/full\#supplementary-material

Al-Bayssari, C., Gupta, S. K., Dabboussi, F., Hamze, M., and Rolain, J. M. (2015). MUS-2, a novel variant of the chromosome-encoded $\beta$-lactamase MUS-1, from Myroides odoratimimus. New Microbes New Infect. 7, 67-71. doi: 10.1016/j. nmni.2015.06.007

Altizer, S., Ostfeld, R. S., Johnson, P. T. J., Kutz, S., and Harvell, C. D. (2013). Climate change and infectious diseases: from evidence to a predictive framework. Science 341, 514-519. doi: 10.1126/science.1239401

Amato, P., Hennebelle, R., Magand, O., Sancelme, M., Delort, A. M., Barbante, C., et al. (2007). Bacterial characterization of the snow cover at Spitzberg, Svalbard. FEMS Microbiol. Ecol. 59, 255-264. doi: 10.1111/j.1574-6941.2006.00198.x 
Anesio, A. M., and Laybourn-Parry, J. (2012). Glaciers and ice sheets as a biome. Trends Ecol. Evol. 27, 219-225. doi: 10.1016/j.tree.2011.09.012

Asam, D., Mauerer, S., and Spellerberg, B. (2015). Streptolysin S of Streptococcus anginosus exhibits broad-range hemolytic activity. Med. Microbiol. Immunol. 204, 227-237. doi: 10.1007/s00430-014-0363-0

Atlas, R. (2010). Handbook of Microbiological Media, 4th Edn. Washington, D.C: ASM Press, doi: 10.1201/ebk1439804063

Bayley, H. (1997). Toxin structure: part of a hole? Curr. Biol. 7, R763-R767. doi: 10.1016/S0960-9822(06)00399-X

Bernheimer, A. (1974). Interactions between membranes and cytolytic bacterial toxins. Biochim. Biophys. Acta 344, 27-50. doi: 10.1016/0304-4157(74)90007-0

Bevivino, A., Dalmastri, C., Tabacchioni, S., Chiarini, L., Belli, M. L., Piana, S., et al. (2002). Burkholderia cepacia Complex Bacteria from Clinical and Environmental Sources in Italy: Genomovar Status and Distribution of Traits Related to Virulence and Transmissibility. J. Clin. Microbiol. 40, 846-851. doi: 10.1128/JCM.40.3.846-851.2002

Bhakdi, S., Grimminger, F., Suttorp, N., Walmrath, D., and Seeger, W. (1994). Proteinaceous bacterial toxins and pathogenesis of sepsis syndrome and septic shock: the unknown connection. Med. Microbiol. Immunol. 183, 343-344. doi: 10.1007/BF00196684

Billington, S. J., Jost, B. H., and Songer, J. G. (2000). Thiol-activated cytolysins: structure, function and role in pathogenesis. FEMS Microbiol. Lett. 182, 197205. doi: 10.1016/S0378-1097(99)00536-4

Bullen, J. J., Rogers, H. J., Spalding, P. B., and Ward, C. G. (2005). Iron and infection: the heart of the matter. FEMS Immunol. Med. Microbiol. 43, 325-330. doi: 10.1016/j.femsim.2004.11.010

Buxton, R. (2005). Blood Agar Plates and Hemolysis Protocols. Available online at: https://www.asm.org/getattachment/7ec0de2b-bb16-4f6e-ba072aea25a43e76/protocol-2885.pdf (accessed December 19, 2018).

Carr, A., Sledjeski, D. D., Podbielski, A., Boyle, M. D. P., and Kreikemeyer, B. (2001). Similarities between Complement-mediated and Streptolysin S-mediated Hemolysis. J. Biol. Chem. 276, 41790-41796. doi: 10.1074/jbc. M107401200

Cavicchioli, R., Ripple, W. J., Timmis, K. N., Azam, F., Bakken, L. R., Baylis, M., et al. (2019). Scientists' warning to humanity: microorganisms and climate change. Nat. Rev. Microbiol. 17, 569-586. doi: 10.1038/s41579-019-0222-5

Cirz, R. T., and Romesberg, F. E. (2006). Induction and inhibition of ciprofloxacin resistance-conferring mutations in hypermutator bacteria. Antimicrob. Agents Chemother. 50, 220-225. doi: 10.1128/AAC.50.1.220-225.2006

Codjoe, F., and Donkor, E. (2018). Carbapenem resistance: a review. Med. Sci. 6:1. doi: $10.3390 /$ medsci6010001

Davies, J., and Davies, D. (2010). Origins and evolution of antibiotic resistance. Microbiol. Mol. Biol. Rev. 74, 417-433. doi: 10.1128/MMBR.00016-10

Dib, J., Motok, J., Zenoff, V. F., Ordoñez, O., and Farías, M. E. (2008). Occurrence of resistance to antibiotics, UV-B, and arsenic in bacteria isolated from extreme environments in high-altitude (above $4400 \mathrm{~m}$ ) Andean wetlands. Curr. Microbiol. 56, 510-517. doi: 10.1007/s00284-008-9103-2

Doney, S. C., Ruckelshaus, M., Emmett Duffy, J., Barry, J. P., Chan, F., English, C. A., et al. (2012). Climate change impacts on marine ecosystems. Annu. Rev. Mar. Sci. 4, 11-37. doi: 10.1146/annurev-marine-041911-111611

DuMont, A. L., and Torres, V. J. (2014). Cell targeting by the Staphylococcus aureus pore-forming toxins: It's not just about lipids. Trends Microbiol. 22, 21-27. doi: 10.1016/j.tim.2013.10.004

Edgar, R. C. (2004). MUSCLE: multiple sequence alignment with high accuracy and high throughput. Nucleic Acids Res. 32, 1792-1797. doi: 10.1093/nar/gkh340

Edwards, A. (2015). Coming in from the cold: potential microbial threats from the terrestrial cryosphere. Front. Earth Sci. 3:12. doi: 10.3389/feart.2015.00012

Epstein, P. R. (2001). Climate change and emerging infectious diseases. Microbes Infect. 3, 747-754. doi: 10.1016/S1286-4579(01)01429-0

European Committee on Antimicrobial Susceptibility Testing [EUCAST] (2019). Breakpoint Tables for Interpretation of MICs and Zone Diameters - Version 9.0. Available online at: http://www.eucast.org

Favero, D., Furlaneto-Maia, L., França, E. J. G., Góes, H. P., and Furlaneto, M. C. (2014). Hemolytic factor production by clinical isolates of Candida species. Curr. Microbiol. 68, 161-166. doi: 10.1007/s00284-013-0459-6

González-Rodríguez, N., Santos, J. A., Otero, A., and García-López, M.-L. (2007). Cell-associated hemolytic activity in environmental strains of Plesiomonas shigelloides expressing cell-free, iron-influenced extracellular hemolysin. J. Food Prot. 70, 885-890. doi: 10.4315/0362-028X-70.4.885

Graham, D. W., Bergeron, G., Bourassa, M. W., Dickson, J., Gomes, F., Howe, A., et al. (2019). Complexities in understanding antimicrobial resistance across domesticated animal, human, and environmental systems. Ann. N. Y. Acad. Sci. 1441, 17-30. doi: 10.1111/nyas.14036

Gudeta, D. D., Bortolaia, V., Amos, G., Wellington, E. M. H., Brandt, K. K., Poirel, L., et al. (2016). The soil microbiota harbors a diversity of carbapenemhydrolyzing $\beta$-lactamases of potential clinical relevance. Antimicrob. Agents Chemother. 60, 151-161. doi: 10.1128/AAC.01424-15

Hutchins, D. A., Jansson, J. K., Remais, J. V., Rich, V. I., Singh, B. K., and Trivedi, P. (2019). Climate change microbiology - problems and perspectives. Nat. Rev. Microbiol. 17, 391-396. doi: 10.1038/s41579-019-0178-5

Hynes, W., and Sloan, M. (2016). "Secreted extracellular virulence factors," in Streptococcus pyogenes: Basic Biology to Clinical Manifestations, eds J. Ferretti, D. Stevens, and V. Fischetti (Oklahoma City: University of Oklahoma Health Sciences Center), 1-40.

Intergovernmental Panel on Climate Change [IPCC] (2007). "Climate change 2007: impacts, adaptation and vulnerability," in Contribution of Working Group II to the Fourth Assessment Report of the Intergovernmental Panel on Climate Change, eds M. L. Parry, O. F. Canziani, J. P. Palutikof, P. J. van der Linden, and C. E. Hanson (Cambridge: Cambridge University Press). doi: 10.1256/ 004316502320517344

Koczura, R., Mokracka, J., and Makowska, N. (2016). Environmental Isolate of Rahnella aquatilis Harbors Class 1 Integron. Curr. Microbiol. 72, 64-67. doi: 10.1007/s00284-015-0917-4

Krajick, K. (2001). Arctic life, on thin ice. Science 291, 424-425. doi: 10.1126/ science.291.5503.424

Kuai, S., Huang, L., Pei, H., Chen, Y., and Liu, J. (2011). Imipenem resistance due to class a carbapenemase KPC-2 in a Flavobacterium odoratum isolate. J. Med. Microbiol. 60, 1408-1409. doi: 10.1099/jmm.0.029660-0

Kumar, S., Stecher, G., and Tamura, K. (2016). MEGA7: molecular evolutionary genetics analysis version 7.0 for bigger datasets. Mol. Biol. Evol. 33, 1870-1874. doi: $10.1093 / \mathrm{molbev} / \mathrm{msw} 054$

Kurane, I. (2010). The effect of global warming on infectious diseases. Public Health Res. Perspect. 1, 4-9. doi: 10.1016/j.phrp.2010.12.004

Litwin, C. M., and Calderwood, S. B. (1993). Role of iron in regulation of virulence genes. Clin. Microbiol. Rev. 6, 137-149. doi: 10.1128/CMR.6.2.137

Livermore, D. M. (2003). Bacterial resistance: origins, epidemiology, and impact. Clin. Infect. Dis. 36, S11-S23. doi: 10.1086/344654

Madigan, M. T., Martinko, J., Stahl, D., and Clarck, D. (2012). Brock Biology of Microorganisms, 13th Edn. San Francisco, CA: Pearson Higher Education.

Madrid, C., Nieto, J. M., Paytubi, S., Falconi, M., Gualerzi, C. O., and Juárez, A. (2002). Temperature- and H-NS-dependent regulation of a plasmid-encoded virulence operon expressing Escherichia coli hemolysin. J. Bacteriol. 184, 50585066. doi: 10.1128/JB.184.18.5058-5066.2002

Marshall, B. M., Ochieng, D. J., and Levy, S. B. (2009). Commensals: underappreciated reservoir of antibiotic resistance. Microbe 4, 231-238. doi: 10.1128/microbe.4.231.1

Martínez, J. L. (2008). Antibiotics and antibiotic resistance genes in natural environments. Science 321, 365-367. doi: 10.1126/science.1159483

McCann, C. M., Christgen, B., Roberts, J. A., Su, J.-Q., Arnold, K., Gray, N. D., et al. (2019). Understanding drivers of antibiotic resistance genes in High Arctic soil ecosystems. Environment 125, 497-504. doi: 10.1016 j.envint.2019.01.034 doi: 10.1016/j.envint.2019.01.034

Messenger, A. J. M., and Barclay, R. (1983). Bacteria, iron and pathogenicity. Biochem. Mol. Biol. Educ. 11, 54-63. doi: 10.1016/0307-4412(83)90042-0

Mindlin, S. Z., Soina, V. S., Petrova, M. A., and Gorlenko, Z. M. (2008). Isolation of Antibiotic Resistance Bacterial Strains from Eastern Siberia Permafrost Sediments. Russ. J. Genet. 44, 27-34. doi: 10.1134/S1022795408010043

Mir, R. A., Weppelmann, T. A., Johnson, J. A., Archer, D., Morris, J. G., and Jeong, K. C. C. (2016). Identification and characterization of cefotaxime resistant bacteria in beef cattle. PLoS One 11:e0163279. doi: 10.1371/journal. pone.0163279

Mogrovejo-Arias, D. C., Brill, F. H. H., and Wagner, D. (2020). Potentially pathogenic bacteria isolated from diverse habitats in Spitsbergen, Svalbard. Environ. Earth Sci. 79:109. doi: 10.1007/s12665-020-8853-4 
Moyer, C. L., and Morita, R. Y. (2007). Psychrophiles and Psychrotrophs. Encyclopedia of Life Scienes. New York, NY: John Wiley \& Sons, Ltd, doi: 10.1002/9780470015902.a0000402.pub2

Naas, T., Bellais, S., and Nordmann, P. (2003). Molecular and biochemical characterization of a carbapenem-hydrolysing $\beta$-lactamase from Flavobacterium johnsoniae. J. Antimicrob. Chemother. 51, 267-273. doi: $10.1093 /$ jac/dkg069

Nelson, G. J. (1967). Lipid composition of erythrocytes in various mammalian species. Biochim. Biophys. Acta 144, 221-232. doi: 10.1016/0005-2760(67) 90152-X

Okamoto, K., Gotoh, N., and Nishino, T. (2002). Extrusion of penem antibiotics by multicomponent efflux systems MexAB-OprM, MexCD-OprJ, and MexXYOprM of Pseudomonas aeruginosa. Antimicrob. Agents Chemother. 46, 26962699. doi: 10.1128/aac.46.8.2696-2699.2002

Pal, C., Bengtsson-Palme, J., Kristiansson, E., and Larsson, D. G. J. (2016). The structure and diversity of human, animal and environmental resistomes. Microbiome 4, 1-15. doi: 10.1186/s40168-016-0199-5

Papp-Wallace, K. M., Endimiani, A., Taracila, M. A., and Bonomo, R. A. (2011). Carbapenems: past, present, and future. Antimicrob. Agents Chemother. 55, 4943-4960. doi: 10.1128/AAC.00296- 11

Perini, L., Gostinčar, C., Anesio, A. M., Williamson, C., Tranter, M., and Gunde-Cimerman, N. (2019a). Darkening of the Greenland ice sheet: Fungal abundance and diversity are associated with algal bloom. Front. Microbiol. 10:557. doi: 10.3389/fmicb.2019.00557

Perini, L., Gostinčar, C., and Gunde-Cimerman, N. (2019b). Fungal and bacterial diversity of Svalbard subglacial ice. Sci. Rep. 9:20230. doi: 10.1038/s41598-01956290- 5

Perron, G. G., Whyte, L., Turnbaugh, P. J., Goordial, J., Hanage, W. P., Dantas, G., et al. (2015). Functional characterization of bacteria isolated from ancient arctic soil exposes diverse resistance mechanisms to modern antibiotics. PLoS One 10:e0069533. doi: 10.1371/journal.pone.0069533

Post, E., Forchhammer, M. C., Bret-Harte, M. S., Callaghan, T. V., Christensen, T. R., Fox, A. D., et al. (2009). Ecological dynamics across the Arctic associated with recent climate change. Science 325, 1355-1358. doi: 10.1126/science. 1173113

Ramachandran, G. (2013). Gram-positive and gram-negative bacterial toxins in sepsis: a brief review. Virulence 5, 213-218. doi: 10.4161/viru.27024

Rojko, N., and Anderluh, G. (2015). How lipid membranes affect pore forming toxin activity. Acc. Chem. Res. 48, 3073-3079. doi: 10.1021/acs.accounts. 5 b00403

Rossolini, G. M., Condemi, M. A., Pantanella, F., Docquier, J., Amicosante, G., Molecolare, B., et al. (2001). Metallo $\beta$-lactamase producers in environmental microbiota: new molecular class B enzyme in Janthinobacterium lividum. Antimicrob. Agents Chemother. 45, 837-844. doi: 10.1128/aac.45.3.837-844. 2001

Ruimy, R., Meziane-cherif, D., Momcilovic, S., Arlet, G., Andremont, A., Courvalin, P., et al. (2010). RAHN-2, a chromosomal extended-spectrum class A b -lactamase from Rahnella aquatilis. J. Antimicrob. Chemother. 65, 16191623. doi: $10.1093 / \mathrm{jac} / \mathrm{dkq} 178$

Sepčić, K., Zalar, P., and Gunde-Cimerman, N. (2011). Low water activity induces the production of bioactive metabolites in halophilic and halotolerant fungi. Mar. Drugs 9, 43-58. doi: 10.3390/md9010043

Tam, H. K., Wong, C. M. V. L., Yong, S. T., Blamey, J., and González, M. (2015). Multiple-antibiotic-resistant bacteria from the maritime
Antarctic. Polar Biol. 38, 1129-1141. doi: 10.1007/s00300-0151671-6

Tindall, B. J. (2004). Prokaryotic diversity in the Antarctic: the tip of the iceberg. Microb. Ecol. 47, 271-283. doi: 10.1007/s00248-003-1050-7

Tomita, T., and Kamio, Y. (1997). Molecular biology of the pore-forming cytolysins from Staphylococcus aureus, alpha- and gamma-hemolysins and leukocidin. Biosci. Biotechnol. Biochem. 61, 565-572. doi: 10.1271/bbb.61.565

van Duin, D., and Doi, Y. (2017). The global epidemiology of carbapenemaseproducing Enterobacteriaceae. Virulence 8, 460-469. doi: 10.1080/21505594. 2016.1222343

Virtanen, J. A., Cheng, K. H., and Somerharju, P. (1998). Phospholipid composition of the mammalian red cell membrane can be rationalized by a superlattice model. Proc. Natl. Acad. Sci. U.S.A. 95, 4964-4969. doi: 10.1073/pnas.95.9.4964

Wang, S., Xu, L., Chi, X., Li, Y., Kou, Z., Hou, P., et al. (2019). Emergence of NDM-1- and CTX-M-3- producing Raoultella ornithinolytica in human gut microbiota bacterial isolation and identification. Front. Microbiol. 10:2678. doi: $10.3389 /$ fmicb. 2019.02678

Wiebe, W. J., Sheldon, W. M., and Pomeroy, L. R. (1992). Bacterial growth in the cold: evidence for an enhanced substrate requirement. Appl. Environ. Microbiol. 58, 359-364. doi: 10.1128/aem.58.1.359-364.1992

Windberger, U., Bartholovitsch, A., Plasenzotti, R., Korak, K. J., and Heinze, G. (2003). Whole blood viscosity, plasma viscosity and erythrocyte aggregation in nine mammalian species: reference values and comparison of data. Exp. Physiol. 88, 431-440. doi: 10.1113/eph8802496

World Health Organization [WHO] (2014). Antimicrobial Resistance Global Report on Surveillance. Geneva: World Health Organization.

Yeh, E., Pinsky, B. A., Banaei, N., and Baron, E. J. (2009). Hair sheep blood, citrated or defibrinated, fulfills all requirements of blood agar for diagnostic microbiology laboratory tests. PLoS One 4:e6141. doi: 10.1371/journal.pone. 0006141

Yuan, M., Yu, Y., Li, H. R., Dong, N., and Zhang, X. H. (2014). Phylogenetic diversity and biological activity of Actinobacteria isolated from the Chukchi Shelf marine sediments in the Arctic ocean. Mar. Drugs 12, 1281-1297. doi: $10.3390 / \mathrm{md} 12031281$

Zughaier, S. M., and Cornelis, P. (2018). Editorial: role of iron in bacterial pathogenesis. Front. Cell. Infect. Microbiol. 8:344. doi: 10.3389/fcimb.2018. 00344

Conflict of Interest: DM was employed by Dr. Brill + Partner GmbH as part of a research network (European Union's Horizon 2020 Research and Innovation Programme, Marie Skłodowska-Curie grant agreement no. 675546). FB is Managing Director of Dr. Brill + Partner GmbH.

The remaining authors declare that the research was conducted in the absence of any commercial or financial relationships that could be construed as a potential conflict of interest.

Copyright (C) 2020 Mogrovejo, Perini, Gostinčar, Sepčić, Turk, Ambrožič-Avguštin, Brill and Gunde-Cimerman. This is an open-access article distributed under the terms of the Creative Commons Attribution License (CC BY). The use, distribution or reproduction in other forums is permitted, provided the original author(s) and the copyright owner(s) are credited and that the original publication in this journal is cited, in accordance with accepted academic practice. No use, distribution or reproduction is permitted which does not comply with these terms. 